\title{
The relation between kinematic synergy to stabilize the center of mass during walking and future fall risks: a 1-year longitudinal study
}

Momoko Yamagata ${ }^{1,2,3^{*}}$, Hiroshige Tateuchi ${ }^{2}$, Itsuroh Shimizu ${ }^{4}$, Junya Saeki ${ }^{2,3,5}$ and Noriaki Ichihashi ${ }^{2}$

\begin{abstract}
Background: Incorrect body weight shifting is a frequent cause of falls, and the control of the whole-body center of mass (CoM) by segmental coordination is essential during walking. Uncontrolled manifold (UCM) analysis is a method of examining the relation between variance in segmental coordination and CoM stability. However, no prospective cohort study has thoroughly investigated how variance in segmental configurations to stabilize the CoM relates to future falls. This study explored whether variance to stabilize the CoM was related to future falls.

Methods: At the baseline visit, 30 community-dwelling older adults walked 20 times on a 6-m walkway. Using kinematic data collected during walking by a three-dimensional motion capture system, UCM analysis was performed to investigate how segmental configuration contributes to CoM stability in the frontal plane. One year after the baseline visit, we evaluated whether the subjects experienced falls. Twelve subjects had experienced falls, and 16 had not. Comparisons of variance between older adults with and without falls were conducted by covariate analysis.

Results: No significant differences in variance were found in the mediolateral direction, whereas in the vertical direction, older adults with fall experiences had a greater variance, reflecting an unstable CoM, than those with no fall experiences.

Conclusions: We verified that the high variance in segmental configurations that destabilize the CoM in the vertical direction was related to future falls. The variables of UCM analysis can be useful for evaluating fall risk.
\end{abstract}

Keywords: Falls, Aging, Center of mass, Segmental coordination, Uncontrolled manifold

\footnotetext{
* Correspondence: myamagata@people.kobe-u.ac.jp

${ }^{1}$ Graduate School of Human Development and Environment, Kobe University, 3-11 Tsurukabuto, Nada-ku, Kobe, Hyogo 657-0011, Japan

${ }^{2}$ Graduate School of Medicine, Kyoto University, 53 Kawahara-cho, Shogoin, Sakyo, Kyoto 606-8507, Japan

Full list of author information is available at the end of the article
}

(c) The Author(s). 2021 Open Access This article is licensed under a Creative Commons Attribution 4.0 International License, which permits use, sharing, adaptation, distribution and reproduction in any medium or format, as long as you give appropriate credit to the original author(s) and the source, provide a link to the Creative Commons licence, and indicate if changes were made. The images or other third party material in this article are included in the article's Creative Commons licence, unless indicated otherwise in a credit line to the material. If material is not included in the article's Creative Commons licence and your intended use is not permitted by statutory regulation or exceeds the permitted use, you will need to obtain permission directly from the copyright holder. To view a copy of this licence, visit http://creativecommons.org/licenses/by/4.0/ The Creative Commons Public Domain Dedication waiver (http://creativecommons.org/publicdomain/zero/1.0/) applies to the data made available in this article, unless otherwise stated in a credit line to the data. 


\section{Background}

Falls in older adults have several causes and lead to increased medical expenses and fatal injuries [1]. Given that most falls occur due to moving the center of mass (CoM) outside the base of support following tripping and slipping, a well-controlled CoM is essential for successful walking. In particular, the unstable postural control and falls in the frontal plane is a great risk of hip fracture, leading to low quality of life and permanent disability $[2,3]$.

The body segments move in a coordinated manner to control the CoM trajectory during walking, and synergistic control of the abundant body segments is necessary to succeed in the walking task [4]. The strength of synergy can be quantified using uncontrolled manifold (UCM) analysis [5]. The synergy calculated by UCM analysis is defined as a neural organization that ensures the coordination of the elements (i.e., body segments in this study) to stabilize the important performance variable in each task (i.e., CoM trajectory during walking in this study) [6]. Using UCM analysis, the segment variance across repetitive tasks is categorized into two types of variance: variance that reflects a stable performance variable $\left(\mathrm{V}_{\mathrm{UCM}}\right)$ and variance that reflects an unstable performance variable $\left(\mathrm{V}_{\mathrm{ORT}}\right)$. The synergy index computed from $\mathrm{V}_{\mathrm{UCM}}$ and $\mathrm{V}_{\mathrm{ORT}}$ is a measure to quantify the strength of synergy that contributes to the stability of the performance variable [6]. A high synergy index resulting from an increase in $\mathrm{V}_{\mathrm{UCM}}$ or decrease in $\mathrm{V}_{\mathrm{ORT}}$ reflects a strong synergy, implying that an abundant set of elements, i.e., body segments, work together in a coordinated manner to control task-specific performance variables, i.e., CoM trajectories.

Previously, we explored the relationship between falls and UCM indices i.e., $\mathrm{V}_{\mathrm{UCM}}, \mathrm{V}_{\mathrm{ORT}}$, and synergy index, using the swing foot position as a performance variable [7]. We found that older adults with a fall history exhibited a higher synergy index than older adults with no fall history, implying that older adults with a fall history use high segment coordination to maintain the stability of swing foot trajectories. Similar results were observed for stroke patients and older adults with a high risk of future falls [8, 9]. Such a person, however, is not a "good walker" and is very unlikely to have higher walking stability than a healthy person. While control of the swing foot is needed as an end-effector of a multiple-degree-of-freedom system, once the CoM becomes unstable, the body segments, including lower limb segments, have to be adjusted to maintain posture balance. Thus, the preferential control of swing foot and the excessive-high segmental configurations to stabilize swing foot during walking might lead to the failure of CoM control instead, that is, a decrease in synergy index stabilizing CoM position [10]. However, no study has investigated the relationship between fall experiences and UCM indices to control CoM trajectories.

The purpose of this prospective cohort study was to determine whether UCM indices that reflect the stable CoM trajectory in the frontal plane are related to future fall risk. Our hypothesis was that the low segment flexibility pattern - that is, high $\mathrm{V}_{\mathrm{ORT}}$, low $\mathrm{V}_{\mathrm{UCM}}$, and low synergy index - at the baseline visit is related to a high risk of falling in the future.

\section{Methods}

\section{Subjects}

Community-dwelling older adults who were at least 60 years old were recruited via flyers. Thirty volunteers participated, and they gave written informed consent according to the procedure approved by the Research Ethics Committee of Kyoto University. The inclusion criteria, which were evaluated via interview, were as follows: a person without neurological disorders or musculoskeletal injuries and a person who could walk without assistance. In this prospective study, we used the same cohort as in our previous study [9].

\section{Experiment at baseline visit}

At the baseline visit, the subjects walked from a marked starting point to an ending point on a $6-\mathrm{m}$ walkway at a comfortable speed 20 times. A 3-5 min rest was provided after every 5 trials to minimize fatigue.

To define the body segment (Fig. 1), a physical therapist with 6 years of experience placed reflective markers on the 7 th cervical vertebra $(\mathrm{C} 7)$ and 10th thoracic vertebra (T10) and on both sides of each subject at the following locations: forehead, greater trochanter, medial and lateral femoral condyles, medial tibia condyle, head of fibula, medial condyle of tibia, medial and lateral malleolus. Kinematic data were collected with eight infrared cameras (VICON MX; Vicon Motion Systems, Oxford) at $100 \mathrm{~Hz}$. We defined the mediolateral direction relative to the global laboratory coordinate system and the frontal plane perpendicular to the global anterior-posterior axis, corresponding to walking orientation.

The data of the single support (SS) phase from toeoff until initial contact in the dominant foot were normalized by time (0-100\%). To include steps during steady-state walking excluding acceleration and deceleration phases, two steps in the dominant foot after excluding the first four steps, i.e., a total of 40 

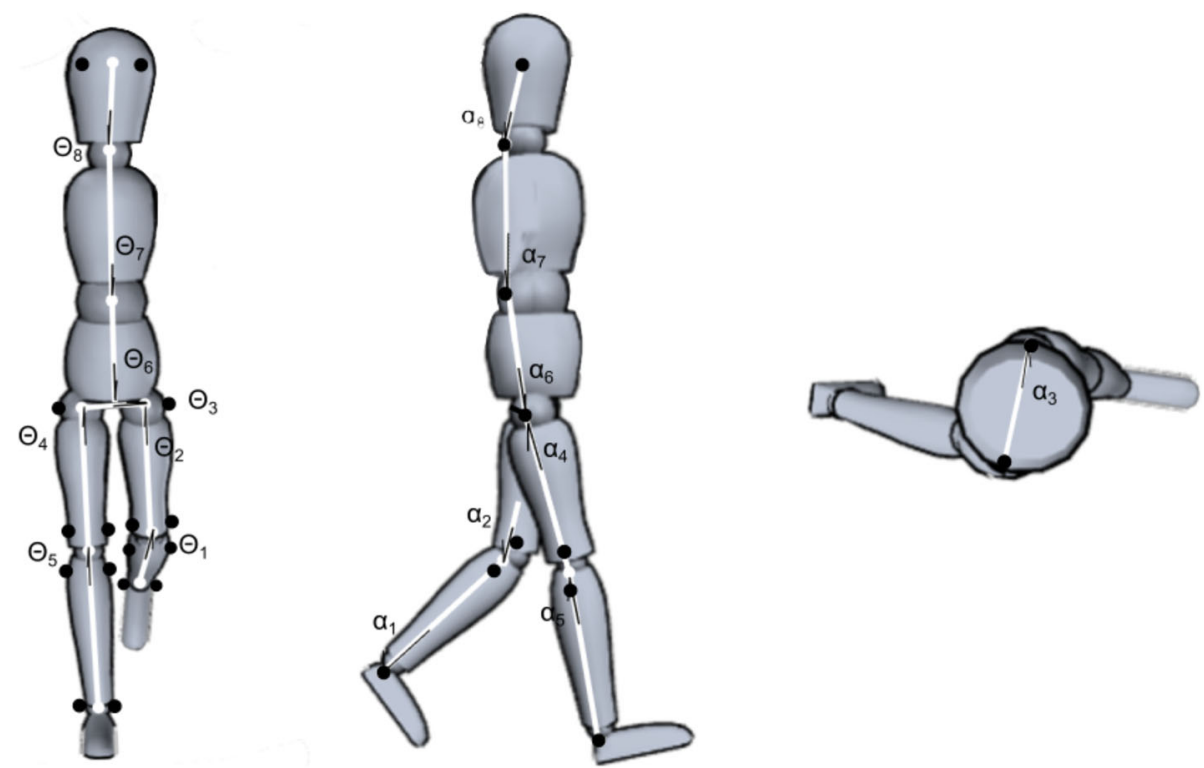

Fig. 1 Illustrations of the segmental angles for the geometric model. Eight segments and 16 degrees of freedom are used for the analysis; 8 degrees of freedom in the frontal plane $\left(\Theta_{1}\right.$ : left shank, $\Theta_{2}$ : left thigh, $\Theta_{3}$ : pelvis, $\Theta_{4}$ : right thigh, $\Theta_{5}$ : right shank, $\Theta_{6}$ : lower trunk, $\Theta_{7}$ : upper trunk, $\Theta_{8}$ : head) and 8 degrees of freedom in sagittal and transverse plane ( $a_{1}$ : left shank, $a_{2}$ : left thigh, $a_{3}:$ pelvis, $a_{4}$ : right thigh, $a_{5}:$ right shank, $a_{6}$ : lower trunk, $a_{7}$ : upper trunk, $a_{8}$ : head). The segments were defined from marker data (black circle) as follows: shank; ankle to knee joint, thigh; knee to hip joint, pelvis; left hip to right hip joint, lower trunk; middle point of both hip joints to T10, upper trunk; T10 to C7, neck; C7 to middle point of foreheads

steady steps, were used for further analysis [11]. Forty steps were chosen as a sufficient repetitive number for a reasonable approximation of UCM indices [12, 13]. Each joint center was calculated from marker data, and the CoM was defined as the position of the sum of each segmental center of mass, i.e., both shanks, both thighs, pelvis, lower trunk, upper trunk, and head [7, 14, 15]. We calculated the average and variability of the CoM position across 40 steps. The variability was calculated as the standard deviation. The fall efficacy scale (FES) was evaluated as physical information at the baseline visit [16]. The FES is a reliable and valid instrument to assess fear of falling, and the FES score is related to walking ability in older adults [16].

\section{Future falls}

One year after the baseline visit, we sent a questionnaire to all subjects asking, "Have you experienced falls within a year?" $[17,18]$. When the subjects had experienced falls, we also asked whether they were injured when falling. The subjects were divided into two groups (older adults with fall experiences: Fallers; older adults without fall experiences: Nonfallers). Further data analysis was conducted on the subjects who answered all questions; in this study, the data of two subjects were excluded because of a lack of responses.

\section{UCM analysis}

Since body segments work in a coordinated manner to control the CoM position during walking, UCM analysis of multi-segment coordination is a feasible and valid method $[5,19]$.

$\mathrm{CoM}$ trajectories in the mediolateral $\left(\mathrm{CoM}_{\mathrm{ML}}\right)$ and vertical $\left(\mathrm{CoM}_{\mathrm{V}}\right)$ directions were used as performance variables as follows $[6,14]$ :

$$
\operatorname{CoM}=x_{0}+\sum_{i=1}^{8} M_{i} x_{i}
$$

where:

$$
\begin{aligned}
& x_{i}=\sum_{j=1}^{i} C_{j} L_{i} \cos \alpha_{j} \sin \theta_{j} \text { for } \operatorname{CoM}_{M L} \\
& x_{i}=\sum_{j=1}^{i} C_{j} L_{i} \cos \alpha_{j} \cos \theta_{j} \text { for } \operatorname{CoM}_{V}
\end{aligned}
$$

and:

$$
C_{j}=1 \text { for } j<i
$$

where $x_{0}$ and $z_{0}$ are the segmental positions of the absolute coordinate system in the ML and V directions, $\Theta_{1}$, 
..., $\Theta_{8}$ are the defined segmental angles in the frontal plane, $\alpha_{1}, \ldots, \alpha_{8}$ are the defined segmental angles in the sagittal and transverse planes, $C_{1}, \ldots, C_{8}$ are the estimated locations of the segmental center of mass, $M_{1}, \ldots, M_{8}$ are segmental masses normalized by total body mass, and $L_{1}, \ldots, L_{8}$ are the lengths of the segments $[14,15]$.

A Jacobian system $(J)$ was used to link the changes in elemental variables (segmental angles in 16 DoFs) and changes in the performance variable (CoM trajectory). $J$ is the matrix of partial derivatives of changes in the CoM trajectory with respect to segmental angles, and the null space $(\varepsilon)$ is the $(n-d)$ vector represented by the dimensions in the segmental configuration space $(n=$ 16) and CoM trajectory $(d=1)$. At every portion of the SS phase, the differences between the segmental configurations and their mean $(\theta-\bar{\theta})$ were projected onto the null space:

$$
\theta_{\text {UCM }}=\sum_{i=1}^{n-d}(\theta-\bar{\theta}) * \varepsilon_{i}
$$

and the space orthogonal to the null space:

$$
\theta_{\text {ORT }}=(\theta-\bar{\theta})-\theta_{\text {UCM }}
$$

The variance in the segment configuration that does not affect the $\mathrm{CoM}_{M L}$ or $\mathrm{CoM}_{\mathrm{V}}\left(V_{U C M}\right)$ was calculated as the average of the squared length of $\theta_{U C M}$ across 40 steps, and normalized by the DoFs within the UCM subspace:

$$
V_{U C M}=(n-d)^{-1} * N^{-1} * \sum\left(\theta_{U C M}\right)^{2}
$$

The variance in the segment configuration that affects the $\mathrm{CoM}_{\mathrm{ML}}$ or $\mathrm{CoM}_{\mathrm{V}}\left(V_{O R T}\right)$ was calculated as the average of the squared length of $\theta_{\text {ORT }}$ across 40 steps, and normalized by the DoFs within the orthogonal subspace:

$$
V_{O R T}=d^{-1} * N^{-1} * \sum\left(\theta_{O R T}\right)^{2}
$$

$\Delta \mathrm{V}$ was computed from $V_{U C M}$ and $V_{O R T}$ as below:

$$
\Delta \mathrm{V}=\frac{V_{U C M}-V_{O R T}}{V_{T O T}}
$$

where

$$
V_{T O T}=\left(\frac{1}{n}\right)\left(d V_{O R T}+(n-d) V_{U C M}\right)
$$

For a normal distribution, Fisher's $z$-transformation was applied to $\Delta \mathrm{V}$ according to previous studies $\left(\Delta V_{Z}\right)[20]$.
SS includes large alterations in kinematics and kinetics [21], and changes in the inverted $U$-shaped curve of $\Delta V_{Z}$ were expected $[7,8]$; thus, the SS phase was divided into the first $1 / 3$ (Early SS), second $1 / 3$ (Mid SS), and third $1 / 3$ (Late SS). For further analysis, the average UCM indices during each phase were calculated.

\section{Statistical analysis}

To test the effects of CoM position and CoM variability during the three SS phases on future falls, two-way ANOVAs (Phase: Early-, Mid-, Late-SS phases, and Group: Faller and Nonfaller) were performed.

To test the effects of Phase (Early-, Mid-, and Late-SS phase) and Group (Faller and Nonfaller) on UCM indices, multivariate analysis of covariance (MANCOVA) adjusted for walking speed was performed in the ML and $\mathrm{V}$ directions separately. The walking speed was used for adjustment based on a previous study that revealed the effects of walking speed on UCM indices [8, 22]. When significant major effects or interactions were detected, we performed post hoc comparisons. All analyses were performed with SPSS (Version 18, PASW Statistics, Chicago), and the significance level was set at $p=0.05$.

As secondary tests, we calculated Spearman's correlation coefficient to explore the relations between UCM indices for CoM trajectory and two factors: UCM indices for swing foot trajectory calculated using a previous geometric model [7]; and the FES score for the fear of falling. The relations between UCM indices for the CoM trajectory and swing foot trajectory reveal whether the preferential control of swing foot leads to the failure of CoM control instead. Considering that fear of falling changes gait patterns such as stiffening strategy [23], the relations of UCM indices for the CoM trajectory with the FES score would also provide important implications to develop a deeper understanding of falling mechanisms.

Before statistical analysis, the data were tested for statistical assumptions of normality and sphericity. For nonnormal or nonspherical data, we used logtransformation or the Greenhouse-Geisser correction, respectively.

\section{Results}

Two subjects who provided no responses on the questionnaire were excluded from the analyses. The subjects were divided into Faller $(n=12)$ and Nonfaller $(n=16)$ groups. Physical characteristics are shown in Table 1. Walking speed was lower in Fallers than in Nonfallers $(p=0.033)$, but the other characteristics of Fallers were similar to those of Nonfallers. $\mathrm{CoM}_{\mathrm{ML}}$ displacements during Early- and Late-SS phases were significantly larger than those during the Mid-SS phase (Phase effect: $\mathrm{F}$ $(2,52)=24.7 ; p<0.001$, Fig. 2a). $\mathrm{CoM}_{\mathrm{V}}$ displacements 
Table 1 Physical characteristics

\begin{tabular}{lll}
\hline & Nonfaller $(\mathbf{n}=\mathbf{1 6})$ & Faller $(\boldsymbol{n}=\mathbf{1 2})$ \\
\hline Age (years) & $73.8 \pm 7.9$ & $78.0 \pm 4.7$ \\
Height $(\mathrm{m})$ & $1.6 \pm 0.08$ & $1.54 \pm 0.11$ \\
Weight $(\mathrm{kg})$ & $58.4 \pm 8.3$ & $52.2 \pm 8.1$ \\
BMl & $22.7 \pm 2.5$ & $21.9 \pm 2.2$ \\
Gait Velocity $(\mathrm{m} / \mathrm{s}){ }^{*}$ & $1.3 \pm 0.1$ & $1.1 \pm 0.1$ \\
FES score & $34.9 \pm 4.4$ & $33.3 \pm 4.5$ \\
\hline
\end{tabular}

${ }^{*} p<=0.05$ between Nonfaller and Faller

were greater in the Mid-SS phase than in the Late-SS phase and greater in the Late-SS phase than in the Early-SS phase (Phase effect: F $(2,52)=83.8 ; p<0.001$, Fig. $2 b)$. $\mathrm{CoM}_{\mathrm{ML}}$ variability was greater in the Late-SS phase than in the Early-SS phase and greater in the Early-SS phase than in the Mid-SS phase (Phase effect: F $(2,52)=85.5 ; p<0.001$, Fig. 2c). $\mathrm{CoM}_{\mathrm{V}}$ variability was significantly greater in the Early-SS phase than in the
Late-SS and Mid-SS phases (Phase effect: F $(2,52)=26.1$; $p<0.001$, Fig. 2d). No Group effect or interaction was found in CoM displacements and variabilities.

Figure 3 shows the average UCM indices during each phase. Phase effects were seen in $\mathrm{V}_{\mathrm{ORT}}$ and $\Delta \mathrm{V}_{\mathrm{Z}}$ in the $\mathrm{V}$ direction $\left(\mathrm{V}_{\text {ORT }}: \mathrm{F}(2,50)=51.56 ; p<0.001, \Delta \mathrm{V}_{\mathrm{Z}}: \mathrm{F}(2\right.$, $50)=3.41 ; p<0.001)$. $\mathrm{V}_{\mathrm{ORT}}$ was significantly greater in the Late-SS than in the Early-SS phase and was greater in the Early-SS phase than in the Mid-SS phase, whereas $\Delta V_{Z}$ was significantly greater in the Mid-SS phase than in the Early-SS phase and greater in the Early-SS phase than in the Late-SS phase. A group effect was seen in the $\mathrm{V}_{\mathrm{ORT}}$ in the $\mathrm{V}$ direction $(\mathrm{F}(1,25)=5.44 ; p=0.028)$; Fallers displayed a significantly greater value than Nonfallers. No major effects in other indices or interactions were found for any indices.

Regarding relations between UCM indices for the CoM trajectory and the other factors, in the Mid SS phase, there was a significant correlation between $\mathrm{V}_{\mathrm{ORT}}$ for vertical (a)

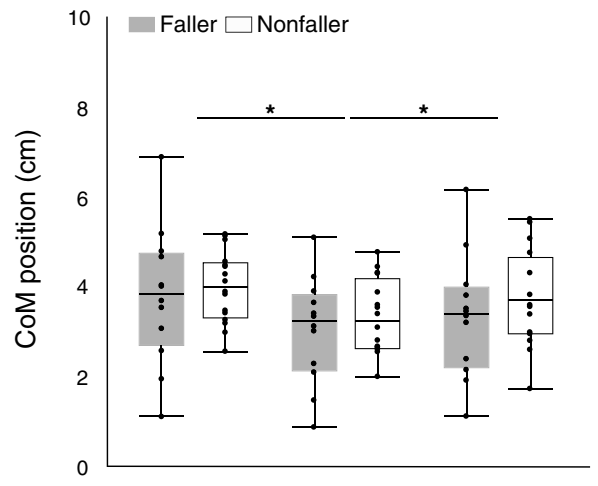

(c)

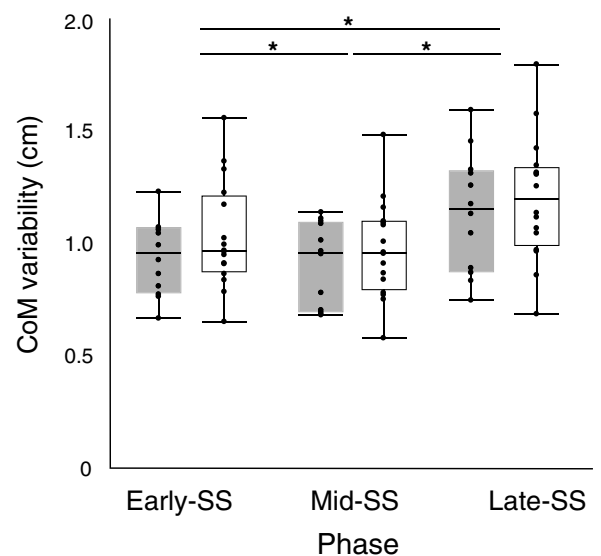

V direction

(b)

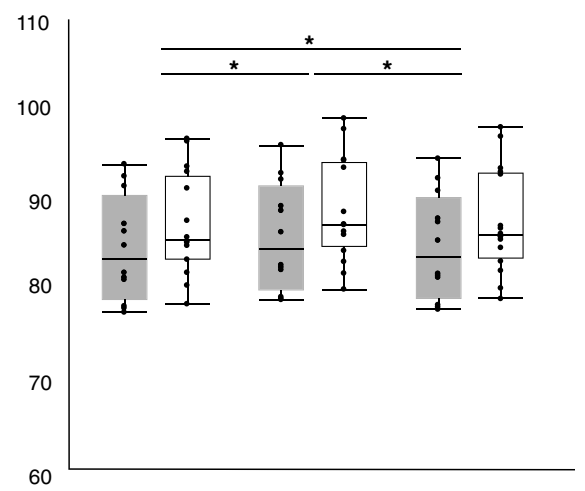

(d)

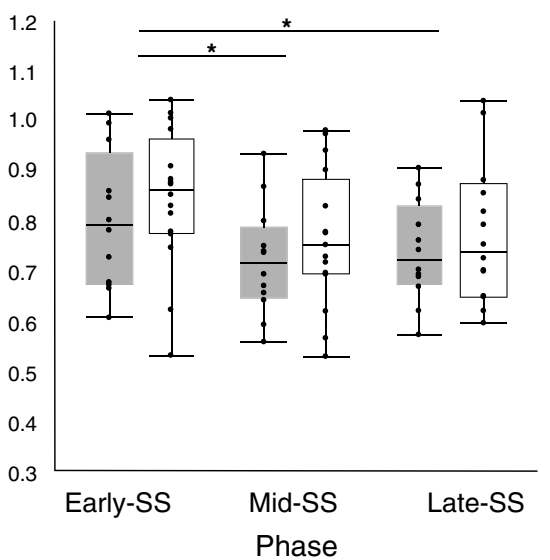

Fig. 2 Box plots of the CoM position ( $\mathbf{a}, \mathbf{b}$ ) and CoM variability (c, d). Box plots of CoM indices in Faller (grey boxes) and Nonfaller (white boxes) for three phases, Early-, Mid-, and Late-SS phases are shown. Dots represent values in each subject. The horizontal line displays the median and the box-edges display the 25th and 75th percentiles. Upper panels: CoM position in the ML (a) and in V (b) directions; Lower panels: CoM variability in the $M L(\mathbf{c})$ and $V(\mathbf{d})$ directions. $V$ direction: vertical direction, ML direction: mediolateral direction, SS: single stance phase. Statistically significant major effects are shown with one star $(p<0.05)$ 


\section{ML direction}

(a)

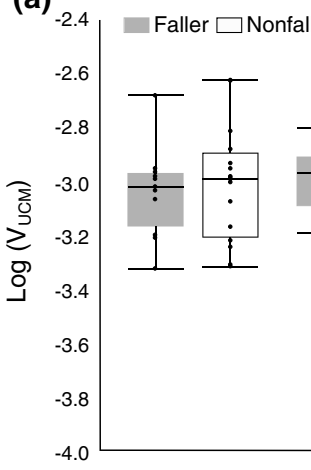

(c)

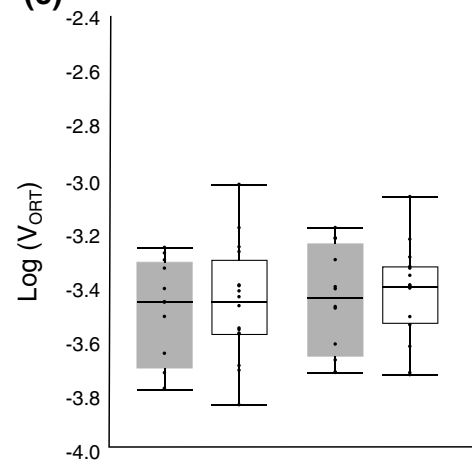

(e) 1

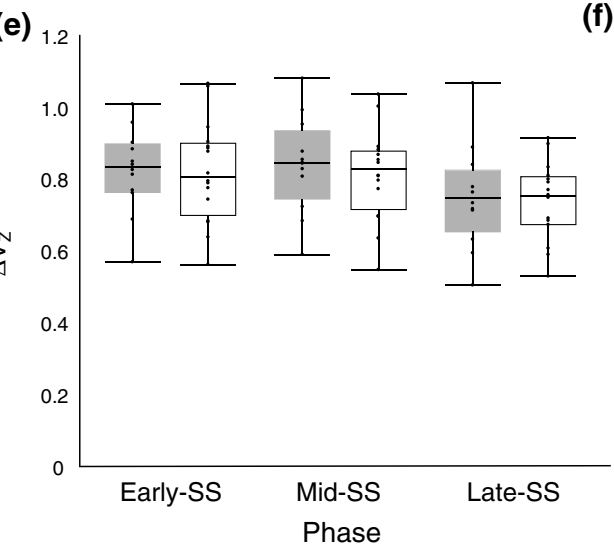

(b)

f)
V direction

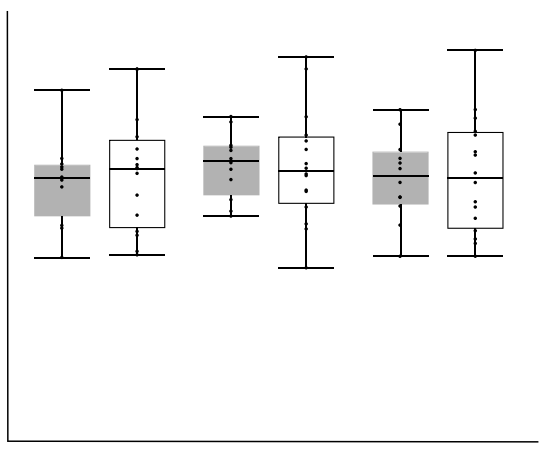

(d)
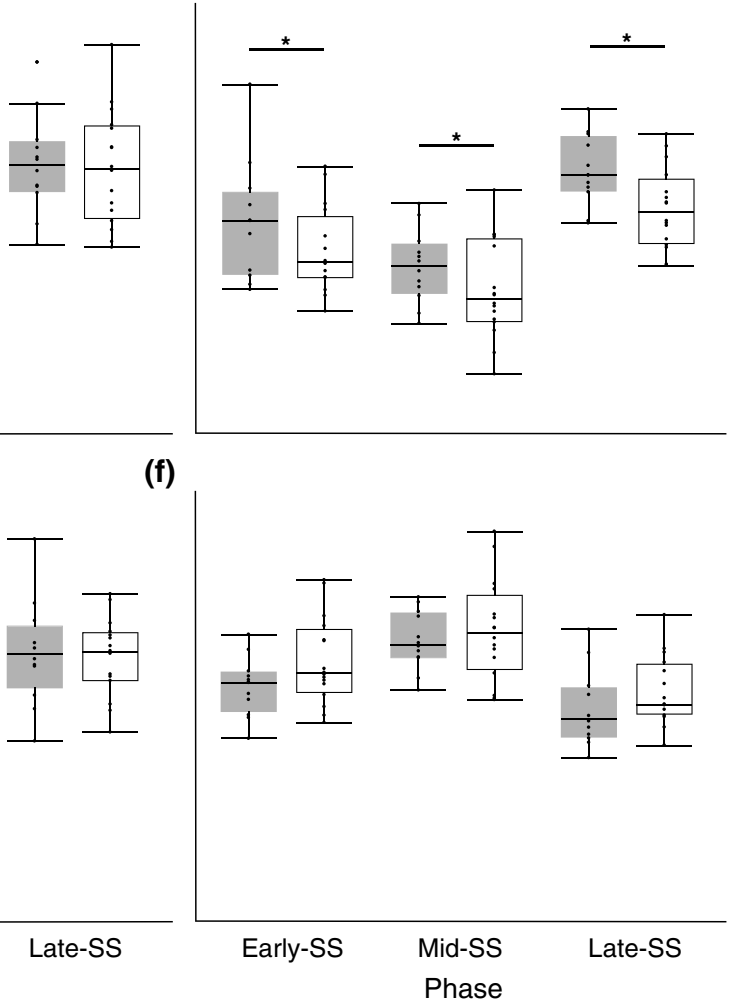

Fig. 3 Box plots of the variance components. Box plots of CoM indices in Faller (grey boxes) and Nonfaller (white boxes) for three phases, Early-, Mid-, and Late-SS phases are shown. Dots represent values in each subject. The horizontal line displays the median and the box-edges display the 25th and 75th percentiles. Upper panels: $V_{U C M}$ in the $M L(\mathbf{a})$ and $V(\mathbf{b})$ directions, Middle panels: $V_{O R T}$ in the ML (c) and V (d) directions, Lower panels: $\Delta V_{Z}$ in the ML (e) and $V(\mathbf{f})$ directions. Statistically significant major effects are shown with one star $(p<0.05)$. For abbreviation, see the caption for Fig. 2

CoM trajectory and $\mathrm{V}_{\mathrm{UCM}}$ for vertical swing foot trajectory ( $\rho=0.40, p=0.03$; Fig. 4$)$, indicating that $\mathrm{V}_{\mathrm{ORT}}$ for the vertical CoM trajectory increased with an increase in $\mathrm{V}_{\mathrm{UCM}}$ for vertical swing foot trajectory. No correlations between UCM indices and FES scores were found.

\section{Discussion}

The purpose of this study was to investigate whether $\mathrm{UCM}$ indices to control the CoM trajectory during walking were related to future falls. The CoM displacement and variability were not significantly different between Fallers and Nonfallers in the ML and V directions. No significant effect of fall experiences was found for UCM indices in the ML direction, and our hypothesis that high $\mathrm{V}_{\mathrm{ORT}}$, low $\mathrm{V}_{\mathrm{UCM}}$, and low synergy index at the baseline visit are related to a high risk of falling in the future was not supported. In the $\mathrm{V}$ direction, the $\mathrm{V}_{\mathrm{ORT}}$ in Fallers was greater than that in 


\section{$\left[10^{-3}\right] \quad$ Early-SS}

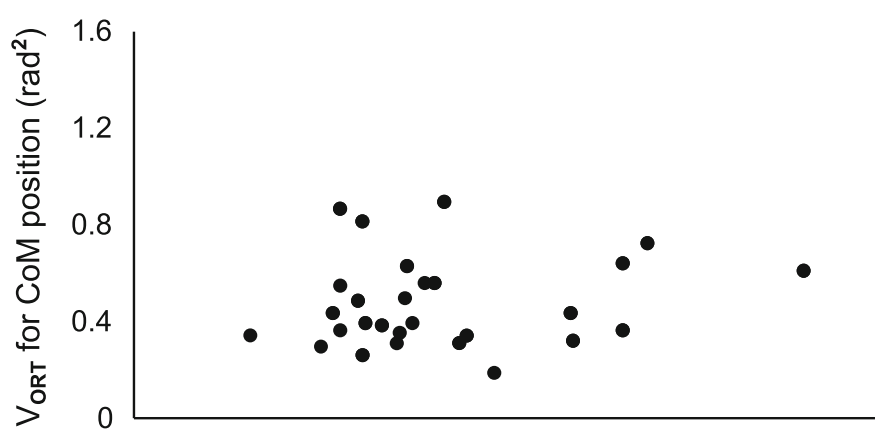

[10 $\quad$ Mid-SS

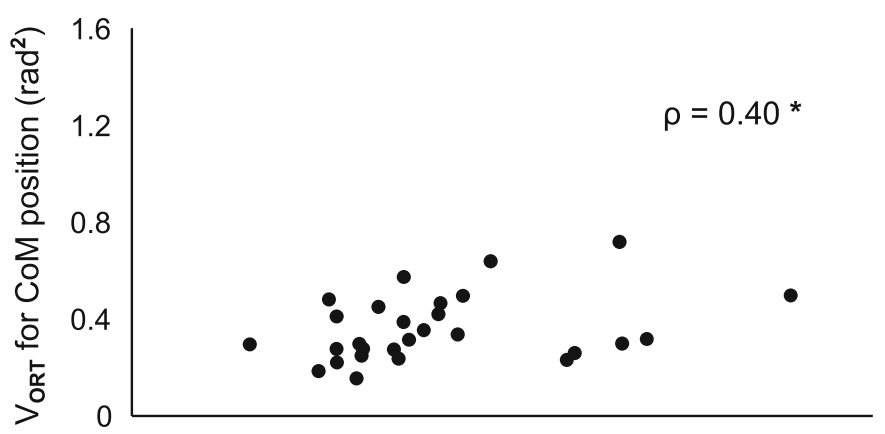

$\left[10^{-3}\right] \quad$ Late-SS

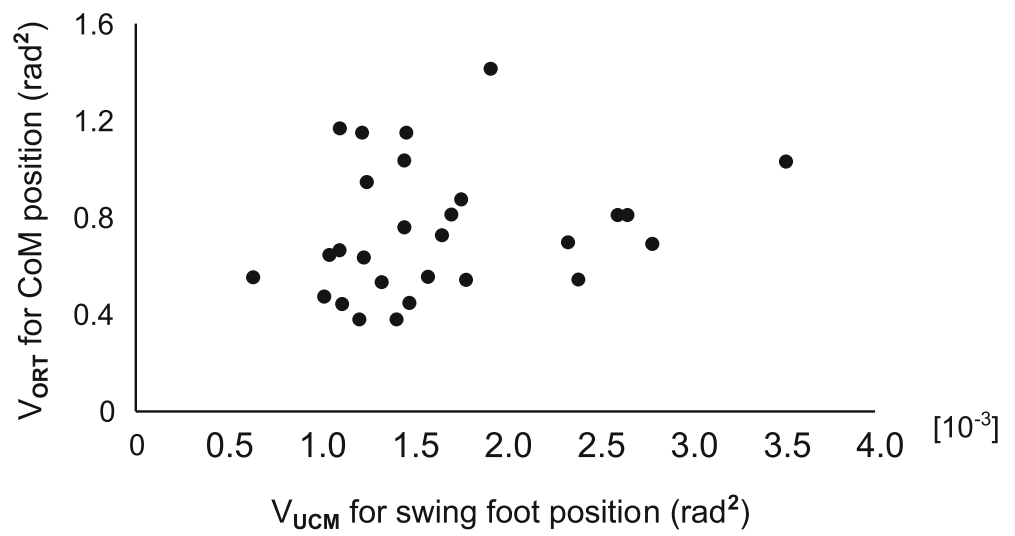

Fig. 4 The correlations between $V_{\text {ORT }}$ for the vertical CoM position and $V_{U C M}$ for the vertical swing foot position. The horizontal axes represent $V_{U C M}$ for swing foot position, and the vertical axes represent $V_{\text {ORT }}$ for COM position. Upper panels: the correlations in the Early-SS phase, Middle panels: the correlations in the Mid-SS phase, Lower panels: the correlations in the Late-SS phase. Statistically, significant correlations are shown with one star $(p<0.05)$. For abbreviation, see the caption for Fig. 2

Nonfallers, with no difference in $\mathrm{V}_{\mathrm{UCM}}$ and $\Delta \mathrm{V}_{\mathrm{Z}}$. Thus, our hypothesis was partly supported in the $\mathrm{V}$ direction.

Previous studies showed that patients with Down syndrome and stroke patients displayed greater $\mathrm{V}_{\mathrm{UCM}}$ to stabilize the CoM than healthy people, in contrast to our findings [5, 19]. Motor and sensory dysfunctions would occur in such patients due to their diseases, and to compensate for the disorders, they might establish a different strategy during walking, such as an increase in $\mathrm{V}_{\mathrm{UCM}}$ to maintain CoM stability. On the other hand, because motor disorders gradually occur with aging, older adults who will experience falls would not be able to use the same compensatory strategy used by patients who suddenly 
experience the disorders, resulting in an increase in $\mathrm{V}_{\text {ORT }}$ and fall experiences.

The $\mathrm{V}_{\text {ORT }}$ in the $\mathrm{V}$ direction was significantly greater in Fallers than in Nonfallers, and the difference was relatively large (effect size f: 0.43). During walking, forward CoM movement while maintaining posture stability against the change in ground reaction force is necessary, especially during the SS phase, when posture is readily rendered unstable [21]. Previous studies have shown that high muscle coactivation and low segment coordination result in low posture stability due to high signaldependent noise and the transmission of perturbations along the vertical body axis [24, 25]. The increased vertical perturbation by external forces, such as ground reaction force, possibly resulted in high $\mathrm{V}_{\text {ORT }}$ that reflects an unstable CoM and high risk of future falls. The development of proper therapies leading to a decrease in $\mathrm{V}_{\text {ORT }}$ is needed for future study.

Despite falls often occurring by incorrect transfer of the CoM to outside the base of support, interestingly, only $\mathrm{V}_{\mathrm{ORT}}$ in the $\mathrm{V}$ direction constituted an adequate index to identify Fallers and Nonfallers. Earlier studies showed a directional difference in the aspects of locomotor control; less able subjects had high variability in the $\mathrm{V}$ direction due to low variability in the ML direction (i.e., Bernsteinian freezing of degrees of freedom) $[26,27]$. Fallers in this study, however, would not use such a walking strategy since $\Delta \mathrm{V}_{\mathrm{Z}}$ reflecting freezing gait was similar to Nonfallers. To develop a deeper understanding of a walking pattern that leads to high $V_{\text {ORT }}$ and future falls, evaluating the segment configurations serving to stabilize anterior-posterior CoM might be needed.

Our previous study observed that older adults with a fall history displayed a highly stable vertical swing foot through the segmental configuration during walking [7], and similar findings were seen in patients with motor disability [10]. In addition to these reports, the current study revealed that a high $\mathrm{V}_{\mathrm{UCM}}$ for vertical swing foot trajectory was related to a high $\mathrm{V}_{\mathrm{ORT}}$ for vertical CoM trajectory in the Mid-SS phase, implying that older adults with well-controlled swing foot trajectory during walking displayed the loss of vertical CoM control instead. While high elevations of swing foot in the Mid-SS phase in older adults are used as one of the conservative walking patterns to prevent trip-related falls [28, 29], in the clinical field, it is necessary to keep in mind the possibility that the excessive control of vertical swing foot trajectory through the segmental configurations may lead to the loss of the control of vertical CoM trajectory, and those walking patterns might lead to falls.

CoM-related variables, walking speed, and the FES have previously been used as indices for fall risks [30-32]. However, there were no differences in CoM displacement, CoM variability, or FES scores between groups. As we found a lower walking speed in Fallers, the $V_{\text {ORT }}$ in Fallers was greater than that in Nonfallers after adjusting for walking speed. The variance in segmental configurations that reflects CoM instability can serve as an index to evaluate potential fall risks independently of walking speed even for subjects with a normal functional level on indices of fall risks, such as CoM-related variables and FES.

There were some limitations in this study. First, a questionnaire was applied to distinguish Fallers and Nonfallers, which might have led to recall bias. Despite the limitations, we believe this common method showed relatively low recall bias, as it occurs over a period of 1 year. Second, there was no information about the causes of falls, although the required performance variable might be different among people with different falling risks. Third, $6 \mathrm{~m}$-walkway might be short to evaluate the steady-state walking. Longer walkway would be better to include sufficiently steady steps for reasonable UCM indices. Additionally, Type II error might have occurred because of the small sample size. For example, the mean age of Fallers was 4 years older than that of Nonfallers; although this difference was not significant, our findings may have been affected by age. Given that CoM movements during walking would change with aging [32], greater $\mathrm{V}_{\mathrm{ORT}}$ in Fallers than in Nonfallers might also be caused by aging. Finally, selection bias might have affected the results, given the high rate of falls in this study.

Other methodological considerations include the geometric model we used in this study. We did not include segments of the upper extremities. Since arm swing is one of the important components for controlling the CoM trajectories during walking and arm swing would change the CoM trajectories [33], a modified model considering the movements of upper extremities is needed in future research. Additionally, we did not focus on the gait in anteroposterior direction. Given major causes of falls such as tripping and slipping will increase the CoM movements in the sagittal plane [34], research on the relationships between sagittal CoM trajectories and segment coordination would reveal important implications for future falls.

\section{Conclusions}

Overall, our study is the first to demonstrate the relationships between kinematic synergy to stabilize the CoM during walking and future fall risks. Although some measures that have been previously used to evaluate fall risk (e.g., CoM variability and FES scores) could not distinguish between older adults with and without future falls, the high variance in segmental 
configurations that affects CoM stability in the vertical direction was related to future falls independent of walking speed. The UCM index can predict future falls and serve as an index for fall risks even in subjects with a normal level on some previous fall risk indices.

\section{Abbreviations}

CoM: Center of mass; BoS: Base of support; SS phase: Single support phase; UCM: Uncontrolled manifold; $V_{\text {UcM: }}$ Variance in the UCM subspace; $V_{\text {ORT: }}$ Variance in the subspace orthogonal to the UCM; C7: 7th cervical vertebra; T10: 10th thoracic vertebra; ML direction: Mediolateral direction; $\mathrm{V}$ direction: Vertical direction

\section{Acknowledgements}

We thank Ibuki Satoko for correcting English.

\section{Authors' contributions}

MY contributed to the study concept and design, subjects' recruitment, data collection, and data analysis. All authors (MY, HT, IS, JS, and NI) had taken part in the discussion and contributed to data interpretation and the manuscript preparation. The final manuscript was approved by all authors.

\section{Funding}

This work was supported by a Grant-in-Aid from the Japan Society for the Promotion of Science Fellows [grant number 17 J02246, 2017].

\section{Availability of data and materials}

All datasets in this study are available from the corresponding author on reasonable request.

\section{Declarations}

\section{Ethics approval and consent to participate}

All procedures have been conducted according to the principles expressed in the Declaration of Helsinki. All subjects gave written informed consent according to the procedure approved by the Research Ethics Committee of Kyoto University (R0433-4).

\section{Consent for publication}

Not applicable.

\section{Competing interests}

The authors declare that they have no competing interests.

\section{Author details \\ ${ }^{1}$ Graduate School of Human Development and Environment, Kobe University, 3-11 Tsurukabuto, Nada-ku, Kobe, Hyogo 657-0011, Japan. ${ }^{2}$ Graduate School of Medicine, Kyoto University, 53 Kawahara-cho, Shogoin, Sakyo, Kyoto 606-8507, Japan. ${ }^{3}$ Research Fellow of the Japan Society for the Promotion of Science, 5-3-1 Kojimachi, Chiyodaku, Tokyo 102-0083, Japan. ${ }^{4}$ Fukui General Clinic, 1-42-1 Nittazuka, Fukui-shi, Fukui 910-0067, Japan. \\ ${ }^{5}$ Faculty of Sport Sciences, Waseda University, 2-579-15 Mikajima, \\ Tokorozawa, Saitama 359-1192, Japan.}

Received: 10 December 2020 Accepted: 31 March 2021

Published online: 13 April 2021

\section{References}

1. Grisso JA, Schwarz DF, Wishner AR, Weene B, Holmes JH, Sutton RL. Injuries in an elderly Inner-City population. J Am Geriatr Soc. 1990;38(12):1326-31. https://doi.org/10.1111/j.1532-5415.1990.tb03456.x.

2. Schwartz AV, Kelsey JL, Sidney S, Grisso JA. Characteristics of falls and risk of hip fracture in elderly men. Osteoporos Int. 1998;8(3):240-6. https://doi. org/10.1007/s001980050060.

3. Dargent-Molina P, Favier F, Grandjean H, Baudoin C, Schott AM, Hausherr E, et al. Fall-related factors and risk of hip fracture: the EPIDOS prospective study. Lancet. 1996:348(9021):145-9. https://doi.org/10.1016/S0140-673 6(96)01440-7.

4. Latash ML. The bliss of motor abundance. Exp Brain Res. 2012:217(1):1-5. https://doi.org/10.1007/s00221-012-3000-4
5. Papi E, Rowe PJ, Pomeroy VM. Analysis of gait within the uncontrolled manifold hypothesis: stabilisation of the Centre of mass during gait. J Biomech. 2015;48(2):324-31. https://doi.org/10.1016/j.jbiomech.2014.11.024.

6. Scholz JP, Schöner G. The uncontrolled manifold concept: identifying control variables for a functional task. Exp Brain Res. 1999;126(3):289-306. https://doi.org/10.1007/s002210050738.

7. Yamagata $M$, Tateuchi $H$, Shimizu I, Ichihashi N. The effects of fall history on kinematic synergy during walking. J Biomech. 2018;82:204-10. https://doi. org/10.1016/j.jbiomech.2018.10.032.

8. Kao P-C, Srivastava S. Mediolateral footpath stabilization during walking in people following stroke. Plos One. 2018;13:1-17.

9. Yamagata M, Tateuchi H, Shimizu I, Saeki J, Ichihashi N. The relation between limb segment coordination during walking and fall history in community-dwelling older adults. J Biomech. 2019;93:94-100. https://doi. org/10.1016/j.jbiomech.2019.06.010.

10. Galna B, Murphy AT, Morris ME. Obstacle crossing in Parkinson's disease: Mediolateral sway of the Centre of mass during level-ground walking and obstacle crossing. Gait Posture. 2013;38(4):790-4. https://doi.org/10.1016/j.ga itpost.2013.03.024.

11. Macfarlane PA, Looney MA. Walkway length determination for steady state walking in young and older adults. Res Q Exerc Sport. 2008;79(2):261-7. https://doi.org/10.1080/02701367.2008.10599489.

12. Rosenblatt NJ, Hurt CP. Recommendation for the minimum number of steps to analyze when performing the uncontrolled manifold analysis on walking data. J Biomech. 2019;85:218-23. https://doi.org/10.1016/j. jbiomech.2019.01.018.

13. Latash MLMML, Levin MMF, Scholz JP, Schöner G. Motor Control Theories and Their Applications. Med (Kaunas, ... . 2010;46:382-92. doi:https://doi. org/10.1016/j.bbi.2008.05.010

14. Tokuda K, Anan M, Takahashi M, Sawada T, Tanimoto K, Kito N, et al. Biomechanical mechanism of lateral trunk lean gait for knee osteoarthritis patients. J Biomech. 2017:66:10-7. https://doi.org/10.1016/j.jbiomech.2017.10.016.

15. Winter DA. Biomechanics and motor control of human movement. 4th ed. Hoboken: Wiley; 2009. https://doi.org/10.1002/9780470549148.

16. Tinetti ME, Richman D, Powell L. Falls efficacy as a measure of fear of falling. J Gerontol Psychol Sci. 1990:45:239-43.

17. Wright RL, Peters DM, Robinson PD, Sitch AJ, Watt TN, Hollands MA. Differences in axial segment reorientation during standing turns predict multiple falls in older adults. Gait Posture. 2012;36(3):541-5. https://doi.org/1 0.1016/j.gaitpost.2012.05.013.

18. Uemura K, Shimada H, Makizako H, Doi T, Tsutsumimoto K, Lee S, et al. Effects of Mild Cognitive Impairment on the Development of Fear of Falling in Older Adults: A Prospective Cohort Study. J Am Med Dir Assoc. 2015;16: 1104.e9-1104.e13. https://doi.org/10.1016/j.jamda.2015.09.014.

19. Black DP, Smith BA, Wu J, Ulrich BD. Uncontrolled manifold analysis of segmental angle variability during walking: preadolescents with and without Down syndrome. Exp Brain Res. 2007:183(4):511-21. https://doi. org/10.1007/s00221-007-1066-1

20. Krishnan V, Rosenblatt NJ, Latash ML, Grabiner MD. The effects of age on stabilization of the mediolateral trajectory of the swing foot. Gait Posture. 2013;38(4):923-8. https://doi.org/10.1016/j.gaitpost.2013.04.023.

21. Perry J. Gait analysis: Normal and pathological function. Thorofare: SLACK Inc; 1992.

22. Singh T, Latash ML. Effects of muscle fatigue on multi-muscle synergies. Exp Brain Res. 2011;214(3):335-50. https://doi.org/10.1007/s00221-011-2831-8.

23. Young WR, Mark WA. How fear of falling can increase fall-risk in older adults: applying psychological theory to practical observations. Gait Posture. 2015;41(1):7-12. https://doi.org/10.1016/j.gaitpost.2014.09.006

24. Valero-Cuevas FJ, Venkadesan M, Todorov E. Structured variability of muscle activations supports the minimal intervention principle of motor control. J Neurophysiol. 2009;102(1):59-68. https://doi.org/10.1152/jn. 90324.2008.

25. Yamagata M, Falaki A, Latash ML. Effects of voluntary agonist-antagonist Coactivation on stability of vertical posture. Mot Control. 2019:23(3):304-26. https://doi.org/10.1123/mc.2018-0038

26. Moe-Nilssen R, Helbostad JL. Interstride trunk acceleration variability but not step width variability can differentiate between fit and frail older adults. Gait Posture. 2005;21(2):164-70. https://doi.org/10.1016/j.gaitpost.2004.01.013.

27. Moe-Nilssen R, Aaslund MK, Hodt-Billington C, Helbostad JL. Gait variability measures may represent different constructs. Gait Posture. 2010;32(1):98101. https://doi.org/10.1016/j.gaitpost.2010.03.019. 
28. Menant JC, Steele JR, Menz HB, Munro BJ, Lord SR. Effects of walking surfaces and footwear on temporo-spatial gait parameters in young and older people. Gait Posture. 2009;29(3):392-7. https://doi.org/10.1016/j.ga itpost.2008.10.057.

29. Winter DA. Foot trajectory in human gait : a precise and multifactorial motor control task. Phys Ther. 1992;72(1):45-53. https://doi.org/10.1093/ptj/ 72.1.45.

30. Pua Y-H, Ong P-H, Clark RA, Matcher DB, Lim EC-W. Falls efficacy, postural balance, and risk for falls in older adults with falls-related emergency department visits: prospective cohort study. BMC Geriatr. 2017;17(1):1-7. https://doi.org/10.1186/s12877-017-0682-2.

31. Lee HJ, Chou LS. Detection of gait instability using the center of mass and center of pressure inclination angles. Arch Phys Med Rehabil. 2006;87(4): 569-75. https://doi.org/10.1016/j.apmr.2005.11.033.

32. Hernández A, Silder A, Heiderscheit BC, Thelen DG. Effect of age on center of mass motion during human walking. Gait Posture. 2009;30(2):217-22. https://doi.org/10.1016/.gaitpost.2009.05.006.

33. Yang HS, Atkins $L T$, Jensen DB, James CR. Effects of constrained arm swing on vertical center of mass displacement during walking. Gait Posture. 2015; 42(4):430-4. https://doi.org/10.1016/j.gaitpost.2015.07.010.

34. Smeesters $C$, Hayes WC, McMahon TA. Disturbance type and gait speed affect fall direction and impact location. J Biomech. 2001;34(3):309-17. https://doi.org/10.1016/50021-9290(00)00200-1.

\section{Publisher's Note}

Springer Nature remains neutral with regard to jurisdictional claims in published maps and institutional affiliations.

Ready to submit your research? Choose BMC and benefit from:

- fast, convenient online submission

- thorough peer review by experienced researchers in your field

- rapid publication on acceptance

- support for research data, including large and complex data types

- gold Open Access which fosters wider collaboration and increased citations

- maximum visibility for your research: over $100 \mathrm{M}$ website views per year

At $\mathrm{BMC}$, research is always in progress.

Learn more biomedcentral.com/submissions 